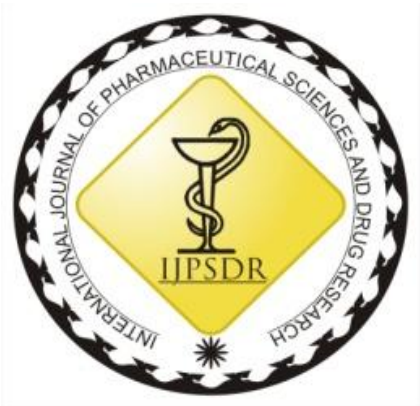

ISSN: 0975-248X

RESEARCH ARTICLE CODEN (USA): IJPSPP

$($ (c) $)$ EY-NC-SA

\title{
Preparation, Characterization of Silver-Nanoparticles from Seed Coat Exudates of Celastrus paniculatus Willd and Their Bactericidal and Biofilm Inhibition Effects
}

\author{
Anil Kumar Moola1, Sundararajan Balasubramani' ${ }^{1}$, Chari Nithya², \\ Ranjitha Kumari Bollipo Diana ${ }^{*}$ \\ ${ }^{1}$ Department of Botany, Bharathidasan University, Tiruchirappalli - 620024, Tamil Nadu, India \\ ${ }^{2}$ Department of Microbiology, Bharathidasan University, Tiruchirappalli - 620 024, Tamil Nadu, India
}

Copyright (C) 2019 Anil Kumar Moola et al. This is an open access article distributed under the terms of the Creative Commons AttributionNonCommercial-ShareAlike 4.0 International License which allows others to remix, tweak, and build upon the work non-commercially, as long as the author is credited and the new creations are licensed under the identical terms.

\begin{abstract}
We are reporting a novel approach for preparing silver nanoparticles with seed coat exudates of Celastrus paniculatus Willd, a medicinal plant traditionally used for the treatment of skin diseases, fever, leprosy and neurological disorders. HPTLC study revealed that aqueous, soluble seed coat exudates contain phenolics, alakaloids and flavonoids. The formation, crystalline nature and morphology of the nanoparticles were identified by UV-Vis spectroscopy, X-ray Diffraction (XRD) analysis, Transmission Electron Microscopy (TEM) and selected-area electron diffraction (SAED). Functional group stretching of aqueous soluble extracts was identified by using FTIR. Results revealed that nanosilver particles are spherical, range in size from 10 to $82 \mathrm{~nm}$ and crystalize in face-centered cubic structures. Surface-enhanced Raman spectra analysis showed that AgNP are capped with bioactive molecules from exudates and that they may act as precursors of the reduction of silver nitrate from the metallic state ( $\left.\mathrm{Ag}^{+}\right)$to the atomic state $\left(\mathrm{Ag}^{0}\right)$. We also examined the minimal inhibitory concentration for bacteria Escherichia coli and Bacillus subtilis using a resazurin color assay. Nanosilver strongly inhibited the bacterial growth, leading to MIC values of $40 \mu \mathrm{g} / \mathrm{ml}$ and $60 \mu \mathrm{g} / \mathrm{ml}$ for the bacteria, respectively. The colony screening method and inhibition kinetics of biofilm formation in the Klebsiella pneumoniae strain were also studied using the tube method and a quantitative microplate assay. SEM analysis and quantification of the EPS revealed a fivefold decrease in concentration in treated compared to untreated. The inhibition response was duly reflected in SEM images.
\end{abstract}

Keywords: Celastrus paniculatus Willd, Seed Coat, Nanosilver, Bactericidal and Biofilm Inhibition.

DOI: 10.25004/IJPSDR.2019.110503

Int. J. Pharm. Sci. Drug Res. 2019; 11(5): 164-173

*Corresponding author: Dr. Ranjitha Kumari Bollipo Diana

Address: Department of Botany, Bharathidasan University, Tiruchirappalli - 620 024, Tamil Nadu, India

Tel.: +91-431-2407061

Fax: +91-431-2407045

E-mail $\bowtie$ : ranjithakumari2004@yahoo.co.in

Relevant conflicts of interest/financial disclosures: The authors declare that the research was conducted in the absence of any commercial or financial relationships that could be construed as a potential conflict of interest.

Received: 03 July, 2019; Revised: 19 August, 2019; Accepted: 21 August, 2019; Published: 25 September, 2019

\section{INTRODUCTION}

Many pathogenic bacteria, such as Escherichia coli, Bacillus subtilis, Klebseilla pneumonia and pseudomonas aeruginosa have developed an enhanced resistance to standard antibiotics like streptomycin and tetracycline. The immense use of antibiotics to treat biofilm 
infections has resulted in the emergence of these antibiotic resistant bacteria. Silver widely known to be highly antimicrobial and the surface-area-to-volume ratio of silver helps it to easily penetrate the bacterial cell wall. [1-3] We hypothesizing that, catalytic oxidation by metallic silver and its reaction with dissolved monovalent silver ions probably contribute to its bactericidal effect.

The biological synthesis of metal nanoparticles, silver nanoparticles in particular by many plants and microorganisms has been studied and explored. Plant parts have been found to mediate synthesis in the safest, healthiest and most effective way [4-5] due to their high number of phytoconstituents, which are involved in the formation of nanosilver. In recent years, leaf extracts such as Grewia flavescens, Skimmia laureola, Vitex negunda and Artemesia vulgaris have been used for the synthesis of metal nanoparticles. [6-12] To the best of our knowledge, previous studies of biological synthesis involved boiling or rupturing of leaf tissue and very few reports [13-14] are available on seed coat exudates. The biological protocol we propose for synthesis is energy efficient and uses a simple extraction process, whereas non-biological methods (chemical and physical) are expensive and occasionally involve the use of hazardous chemicals. This motivated us to carry out this investigation.

In our study, nanosilver was synthesized by using the water-soluble seed coat exudates of Celastrus paniculatus Willd. C. paniculatus Willd is a woody climbing shrub and belongs to the family Celastraceae. The seeds in Ayurveda are used to treat a wide variety of ailments, particularly skin diseases, fever and neurological disorders. [15] The synthesized nanoparticles have been characterized and tested for their antimicrobial efficacy.

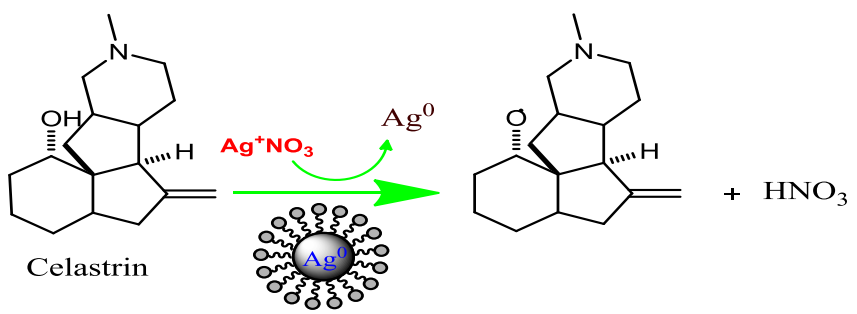

Mechanism 1: Hypothesized mechanism behind formation of Nano Silver

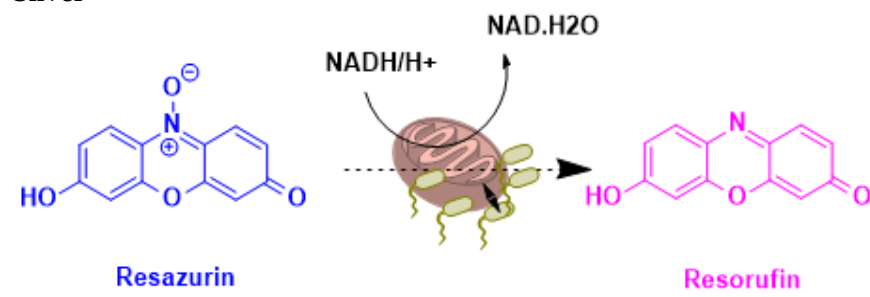

Mechanism 2: Oxidation reduction reaction of resazurin plate assay to determine the MIC value

\section{MATERIALS AND METHODS}

Materials

Fresh Celastrus paniculatus Willd seeds were procured from the Sewa Aushadhi Bhandar, Indore, India. The samples were than authenticated for their correct botanical identity by scientist at Botanical Survey of India, Southern Regional Centre, Coimbatore with voucher specimen number BSI/SRC/5/23/2019/Tech. /111. Reagents, solvents were purchased from HiMedia, Mumbai and Double distilled ultrapure water was used throughout this research.

\section{Isolation and Screening of Phytoconstituents}

Five grams of freshly collected C. paniculatus seeds were transferred into an Erlenmeyer flask containing sterile distilled water $(50 \mathrm{ml})$ and placed in a shaking BOD incubator with a rate of $100 \mathrm{rpm}$ for $30 \mathrm{~min}$ at room temperature. The extract was sterilized by using an MF-Millipore Membrane Filter and stored at $4^{\circ} \mathrm{C}$ for further experimental work.

\section{HPTLC}

HPTLC analysis was performed using the CAMAG HPTLC system (Switzerland). Merck 60G F254 stationary-phase, aluminum-backed, pre-coated silica gel plates with $0.2 \mathrm{~mm}$ thickness were used. Samples were applied as bands $10 \mathrm{~mm}$ from the bottom of the plates using the CAMAG ATS 4. The plates were developed up to $80 \mathrm{~mm}$ in ascending mode at room temperature $\left(28 \pm 2^{\circ} \mathrm{C}\right)$ in a Twin Trough Chamber (CAMAG), which had been previously saturated with mobile-phase toluene-ethyl acetate. After development, the CAMAG TLC Scanner 3 scanned the air-dried plates using a deuterium lamp with win CATS software, resulting in measurements of $254 \mathrm{~nm}$ and 366 nm.

\section{Total Phenolic Content}

Phenolics were estimated by method given by Ainsworth and Gillespie [16] and the phenolic content was calculated as gallic acid equivalents (GAEs)/grams of extract. Briefly, the test sample $(0.5 \mathrm{ml})$ was mixed with $1 \mathrm{ml}$ of Folin and Ciocalteu's phenol reagent, $2 \mathrm{ml}$ of a $700 \mathrm{mM}$ sodium carbonate solution was added and the reaction was kept in the dark for $90 \mathrm{~min}$, after which the UV-visible spectrophotometer measured the absorbance to be $765 \mathrm{~nm}$.

\section{Synthesis of Silver Nanoparticles}

Stable nanosilver were synthesized using an earlier method by Rajasekharreddy et al [17] using different concentrations $(0.5 \mathrm{mM}$ and $1 \mathrm{mM})$ of nanosilver. $\mathrm{AgNO}_{3}$ solutions with aqueous seed exudates were exposed to sunlight for $60 \mathrm{~min}$, and the brown color resulting is confirmed the formation of silver nanoparticles.

\section{Nanosilver Characterization}

The synthesis of AgNPs was monitored by scanning the maximum absorption of the reacted mixture at the wavelength between 300 and $700 \mathrm{~nm}$ on the UV-visible spectrophotometer (UV-2600, Shimadzu). The solution in colloidal form was centrifuged at $14,000 \mathrm{rpm}$ for 10 min at room temperature and the resultant pellet was washed with sterile distilled water and dried in a desiccator. The dried pellet underwent powder X-ray diffraction (PXRD) and optical properties of the nanosilver were studied using an FTIR 
spectrophotometer (PerkinElmer) in the range of 450$4000 \mathrm{~cm}^{-1}$. Surface-enhanced Raman spectroscopy (SERS) was also performed using the XploRA (Jobin Yvon, HORIBA) with a 785-nm laser to confirm the molecules were present to form the nanosilver.

The morphology and crystalline nature of the particles were identified by transmission electron microscope (TEM) and selected-area electron diffraction (SAED) analysis. $5 \mu \mathrm{l}$ of sample was placed onto the copper grid coated with carbon, and a thin film of the sample was made on the grid. Extra sample was removed by keeping the sample under an incandescent light bulb.

\section{Bactericidal activity}

\section{Minimum Inhibitory Concentration (MIC)}

MIC assay was carried out using Elshikh et al [18-19] 96well microtiter plate method with minor modifications. In this study, two of the MTCC quality control strains, namely Gram-negative Escherichia coli (MTCC-405) and Gram-positive Bacillus subtilis (MTCC-736) purchased from MTCC Chandigarh, India. Bacteria were screened against the antibiotic streptomycin (bactericidal in action), and the MIC was examined by observing and recording color changes. Serial dilution $(10-100 \mu \mathrm{g} / \mathrm{ml})$ of the silver nanoparticles representing different concentration of the AgNPs were added to a growth medium $\left(10^{8} \mathrm{CFU} / \mathrm{ml}\right)$ in the 96 well microtiter plate. After the samples were incubated for $16 \mathrm{~h}$ at $37^{\circ} \mathrm{C}$, resazurin dye $(0.010 \%)$ obtained from Hi-Media was serially added to all wells $(10 \mu \mathrm{l}$ per well), and the combined mixture was incubated for another $2 \mathrm{~h}$ so that we could observe a color change from blue to pink (Mechanism 2). Samples that showed no color change scored above the MIC value. A positive control of serially diluted streptomycin $(10-100 \mu \mathrm{g} / \mathrm{ml})$ and a negative control of DMSO were also both taken in wells.

\section{Bactericidal Effects in the Presence of Nanosilver}

Maintenance of tested cultures

Overnight $(\mathrm{O} / \mathrm{N})$ grown cultures in Luria broth at $37^{\circ} \mathrm{C}$ with continuous agitation, Absorbance was set to 0.1, corresponding to $10^{8} \mathrm{CFU} / \mathrm{ml}$ at $600 \mathrm{~nm}$.

\section{Bacterial susceptibility to nanosilver}

E. coli and B. subtilis susceptibility was examined to antibiotics in the presence of nanosilver, we suspended the $\mathrm{O} / \mathrm{N}$ incubated cells in a $0.85 \% \mathrm{NaCl}$ buffer and then added the nanosilver at the desired concentrations: 25, 50 and $100 \mu \mathrm{g} / \mathrm{ml}$. After a predetermined incubation period of $3 \mathrm{~h}$ at room temperature, an aliquot of the suspension was inoculated on nutrient agar plates, and the plates were incubated further at $37^{\circ} \mathrm{C}$ in order to determine the resulting variability based on colony formation on traditional agar plates after incubation for $12 \mathrm{~h}$. Silverand antibiotic-free plates that were incubated under the same conditions were used as controls.

\section{Biofilm inhibition effects of Nanosilver}

Tube Method

Tube method is a qualitative analysis for detection of biofilm form determined by Christensen et al. [20]
Overnight $(\mathrm{O} / \mathrm{N})$ grown Klebsiella isolate was inoculated on culture plates, incubated for $24 \mathrm{~h}$ at $37^{\circ} \mathrm{C}$. The isolates of which biofilm formed on the test tube are stained with $0.1 \%$ crystal violet for $1 \mathrm{~h}$, after planktonic cells are discharged by rinsing twice with phosphate-buffered saline (PBS). Then, crystal violet stained test tubes is rinsed twice with PBS to discharge stain. After air drying of the test tube process, occurrence of visible lines at the bottom of the test tube indicates biofilm production.

\section{Microplate Quantitative Assay}

Microplate quantitative assay is a quantitative method to determine biofilm production by microplate reader. Klebsiella inoculum was inoculated with different concentrations in the range of 25,50, 75 and $100 \mu \mathrm{g} / \mathrm{ml}$ of nanosilver and antibiotic streptomycin (control). Aliquots of $200 \mu 1$ of bacterial suspension are inoculated into 96 well flat-bottomed polystyrene microtiter plates (Tarsons). Microplates are incubated at $24 \mathrm{~h}$ at $37^{\circ} \mathrm{C}$, then each well is stained by adding $25 \mu \mathrm{l}$ of crystal violet for $15 \mathrm{~min}$. Planktonic cells in walls of the microplate are discharged by washing with $200 \mu$ l PBS. The crystal violet absorbed by the biofilm was extracted later with two washes of $200 \mu$ l ethyl alcohol and degree of biofilm formation was measured by taking the absorbance at $540 \mathrm{~nm}$.

\section{Microscopic Observation}

Effect of nanosilver against biofilm formation by Klebsiella pneumoniae was examined by using light and a confocal laser scanning microscope (CLSM). Biofilm formation were allowed on $1 \times 1 \mathrm{~cm}$ glass slides, which were placed into 24 well microtiter plates (in triplicate), incubated at $37^{\circ} \mathrm{C}$ for $24 \mathrm{~h}$. The glass slides were washed with distilled water after being removed from incubation.

Cells bound to the glass slides were stained with $200 \mu \mathrm{l}$ of $0.1 \%(\mathrm{v} / \mathrm{v})$ crystal violet for $15 \mathrm{~min}$ and viewed under a light microscope at 100x magnification and the image was documented by the digital camera attached to the microscope (Carl Zeiss, Jena, Germany). [21]

Biofilms formed on the $1 \times 1 \mathrm{~cm}$ glass slides were stained with $0.01 \%$ acridine orange $(\mathrm{w} / \mathrm{v})$ for $5 \mathrm{~min}$, followed by a brief wash in distilled water. After air drying, the slides were observed under the CLSM (LSM 710, Carl Zeiss, Germany). The 488-nm Ar laser and 500-640 nm band emission filter were used to excite and detect the stained cells (Nithya et al. 2010). [22]

\section{Scanning Electron Microscope (SEM)}

Biofilm formed on the glass slides was fixed with $2.5 \%$ glutaraldehyde for $2 \mathrm{~h}$ at $4^{\circ} \mathrm{C}$ and washed with $0.1 \mathrm{M}$ of a sodium acetate buffer $(\mathrm{pH}$ 7.3). Finally, the dehydrated samples were dried, gold sputtered and examined with the VEGA3 microscope (TESCAN). [21]

\section{Quantification of Exopolysaccharide (EPS)}

EPS was extracted from both treated and untreated pathogens and quantified by using Nithya et al. [22-23] Glass slides immersed in bacterial culture in 24 well polystyrene plates were used to estimate the extra poly saccharide formation. The glass slides were removed 
and washed with $0.9 \% \mathrm{NaCl}(0.5 \mathrm{ml})$ after incubation. An equal volume of concentrated $\mathrm{H}_{2} \mathrm{SO}_{4}$ were added to the cell suspension, incubated for $1 \mathrm{~h}$ in the dark and centrifuged at 10,000 rpm for $10 \mathrm{~min}$. The absorbance of the supernatant was measured at $490 \mathrm{~nm}$.

\section{Statistical Analysis}

All experiments were carried out independently at least six times. Bars representing standard deviation values with average of mean were created using SPSS software, and graphs were plotted using GraphPad Prism 6.1.

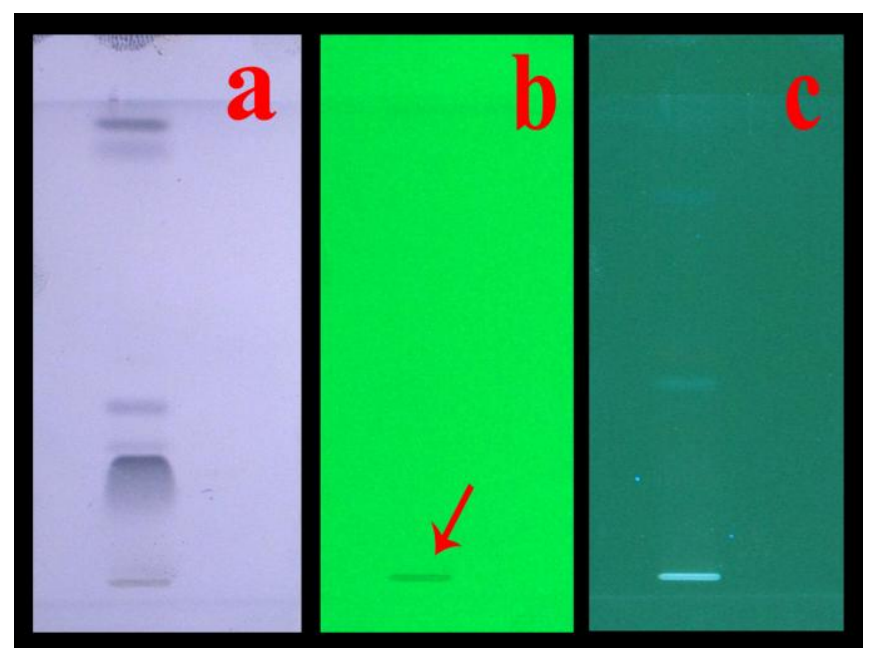

Fig. 1: HPTLC plate seen at a- Visible Light, b- at 254 nm, c- 366 nm.

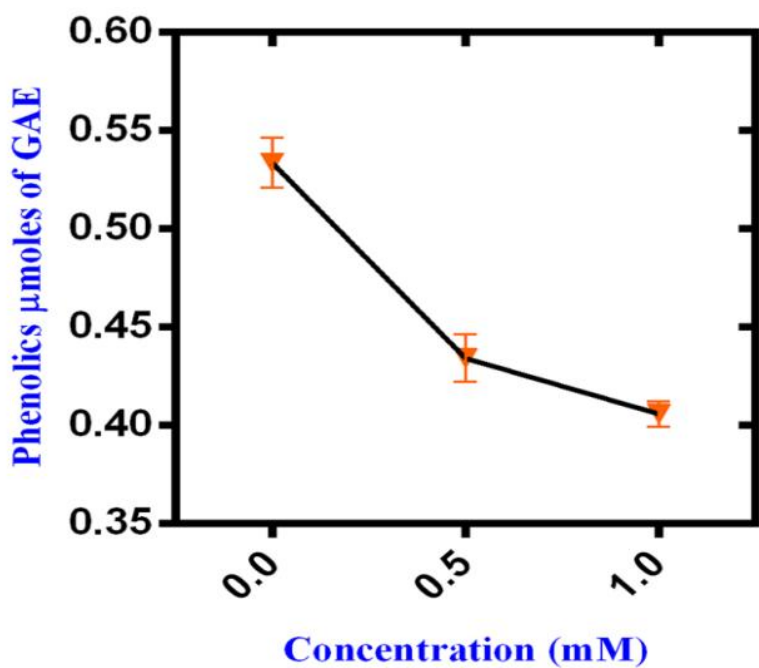

Values represent mean of data collected from three independent experiments and vertical lines on bars represented standard deviation values.

Fig. 2: Phenolic content in $\mathrm{Ag}^{+}$solutions (mM) incubated with Celastrus paniculatus Willd. seed exudates.

\section{RESULTS AND DISCUSSION}

Phytochemical Screening

Tannins, phenolics and alkaloids present in the seed exudates of $C$. paniculatus was analyzed using preliminary phytochemical analysis method (data not shown). For further identification, HPTLC separation of active constituents was done. Different mobile systems for TLC analysis were also tested (Fig. 1). Toluene-ethyl acetate (9:1 ratio) was identified as a suitable mobile phase and RF values were calculated. Recent reports by [2, 24-25] suggest that the reduction of silver ions $\left(\mathrm{Ag}^{+}\right)$to silver atoms $\left(\mathrm{Ag}^{0}\right)$ in the presence of reducing agents is mediated by secondary metabolites and they also play a role of capping agents in the process of stabilizing nanoparticles. These results agree with previous reports [26], in which they clearly recognize that seed coat exudates are a key source of phenolics for the preparation of nanoparticles. Remarkably, in our research, as evidenced in Fig. 2, we observed that there is tremendous decrease in phenolics by the increase in the concentration of nanoparticles.

Synthesis and Characterization of Silver Nanoparticles

C. paniculatus seed coat exudate was mixed into $0 \mathrm{mM}$ (without silver nitrate), $0.5 \mathrm{mM}$ and 1-mM silver nitrate solutions and was incubated at room temperature for 1 $\mathrm{h}$. The formation of nanoparticles is indicated by the change of colorless silver nitrate solution to brown (Fig. 3a). UV-Vis spectroscopy showed the excited surface plasmon resonance (SPR) band [27], with a maximum $420 \mathrm{~nm}$ indicating the existence of silver nanoparticles. Fig. $3 b$ shows that increasing reaction time also increased the peak area this process was clearly observed up to $35 \mathrm{~min}$. PXRD methods were used to evaluate the crystalline nature of the silver nanoparticles. The PXRD profile of the AgNPs, presented in Fig. 4a, exhibits characteristic peaks at scattering angles $(2 \theta)$ of $37.87,44.07,64.26$ and 77.12, corresponding with scattering from the $\left(\begin{array}{lll}1 & 1 & 1\end{array}\right),\left(\begin{array}{lll}2 & 0 & 0\end{array}\right)$, (2 22 0) and (3 11 1) planes respectively. [28] These diffraction peaks represent a face-centered, cubic structure of crystalline silver nanoparticles. All the peaks in the XRD pattern can be indexed as standard Ag crystals, which shows the high purity of the synthesized crystalline silver nanoparticles (JCPDS card no. 89-3722).

FTIR analysis was summarized in Table 1 and Fig. 3c. An evaluation of these results in comparison with earlier reports by Poovizhi et al [29] indicates that phenolics, alkanes and carboxylic acids may be participating in the nanoparticle synthesis and stabilization. The SERS spectrum of nanosilver is shown in Fig. 4b, which identifies the active biomolecules of the extract involved in this process.

Table 1: Spectral Positions of FTIR peaks.

\begin{tabular}{cc}
\hline Center $\left(\mathbf{c m}^{-1}\right)$ & Assignments \\
\hline 3431 & N-H stretching of $1^{\circ}$ and $2^{\circ}$ amines. \\
2924 & O-H stretching of nitro group \\
2850 & C-H stretching of alkanes \\
1561 & N-O stretching of nitro compounds \\
1401 & C-C for aromatics \\
\hline
\end{tabular}

TEM measurements revealed the size and shape of the synthesized nanoparticles (Fig. 5). Their spherical shape was further defined by TEM images of the AgNPs. 

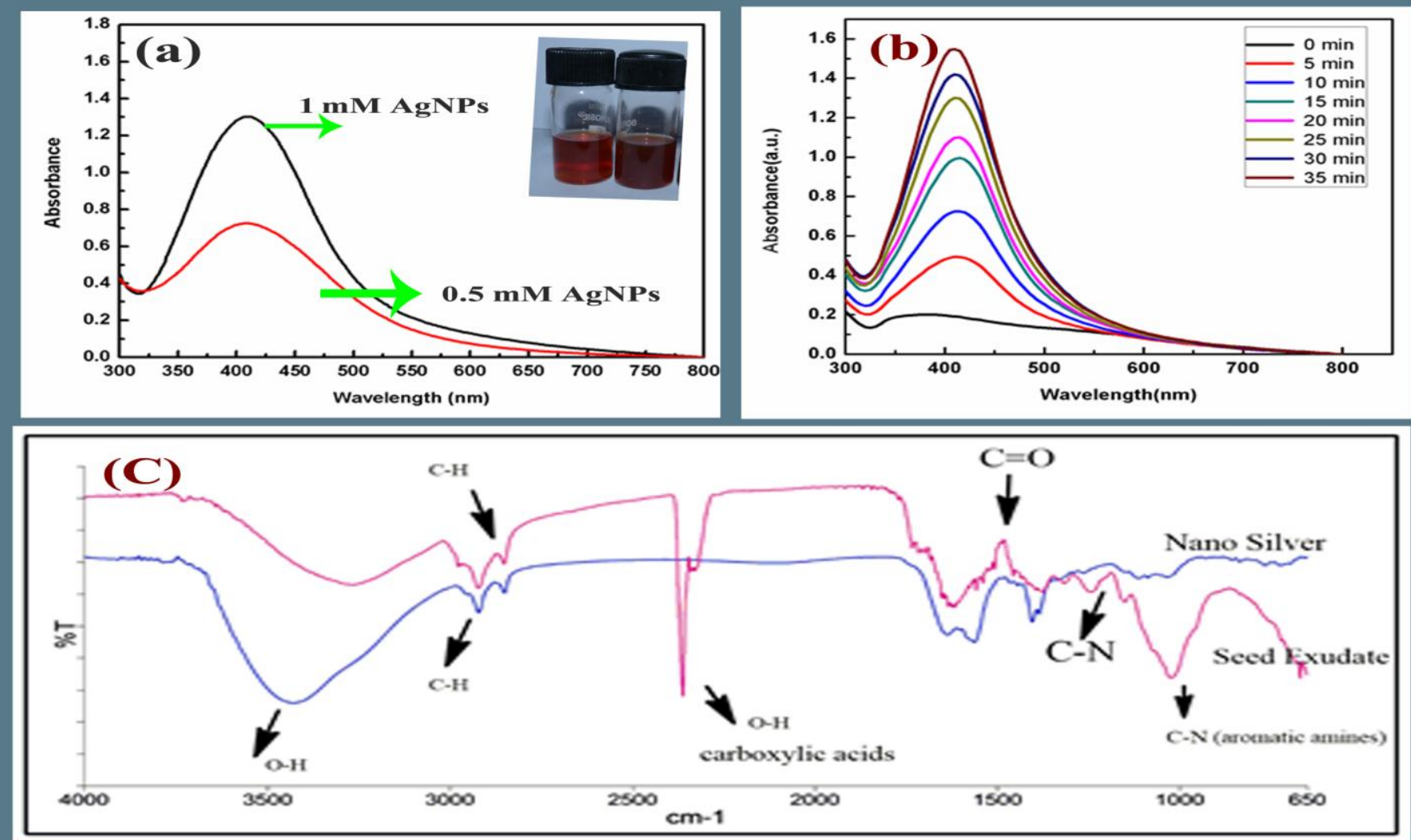

Fig. 3: Characterization of Nano silver by using (a). Uv- vis spectra for silver nanoparticles (b). UV - Visible spectra of silver nanoparticles with different time intervals. (c) FTIR spectra of Silver Nanoparticles
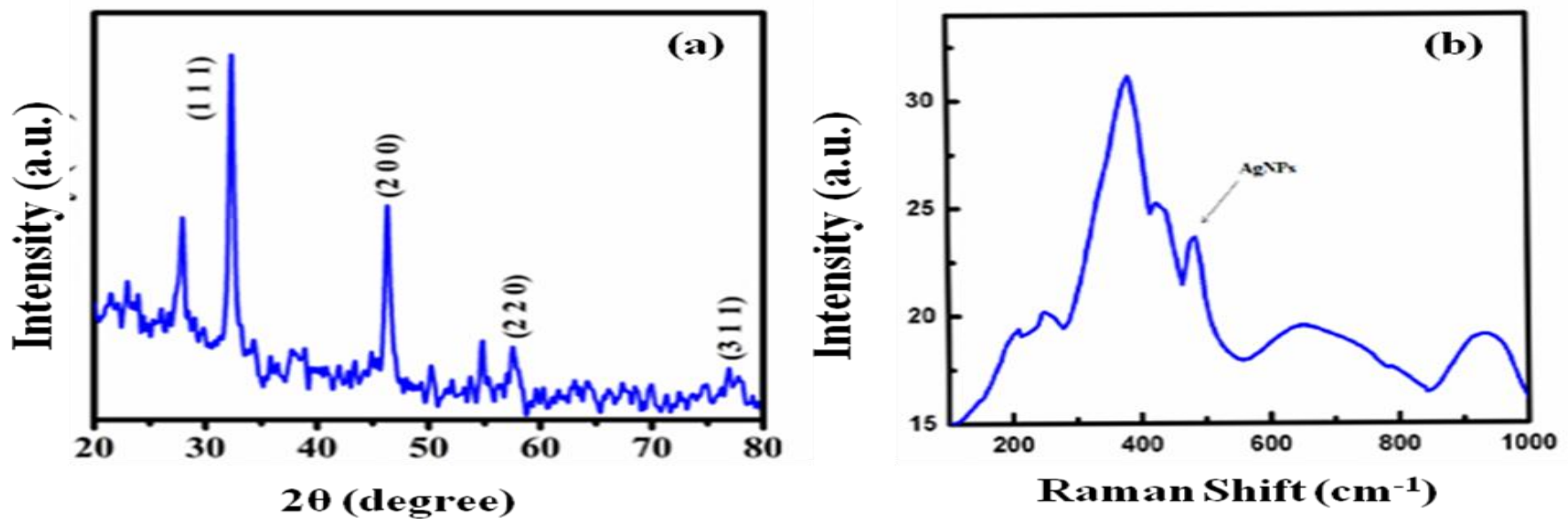

Fig. 4: Characterization of Nano silver by using (a) XRD pattern of silver nanoparticles. (b) SERS spectra for silver nanoparticles.
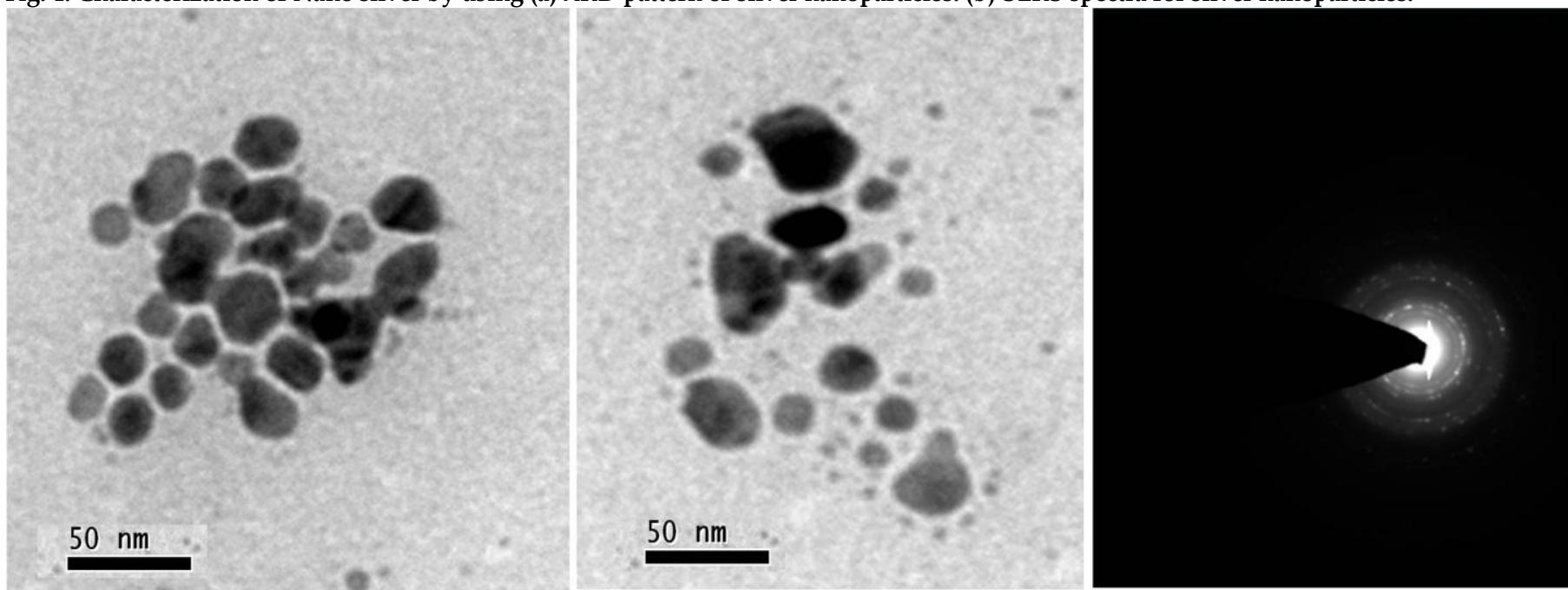

Fig. 5: TEM, SAED patterns of nanoparticles $(0.5 \mathrm{mM})$ of $C$. paniculatus Willd. seed exudates 
The lattice fringes in processed TEM images show that the AgNPs are single crystals and also reveal that the particles have a latticed spacing of $2.37 \AA$ in the $\left(\begin{array}{lll}1 & 1 & 1\end{array}\right)$ plane, matching the d-spacing in the (1 111 ) plane of $\mathrm{Ag}$ with a face-centered cubic shape (FCC). SAED of a single spherical particle also confirmed the monocrystalline nature of AgNPs (Fig. 5). Sizedependent histograms of seed exudate nanosilver showed spherical AgNps with varying sizes between 20-50 nm, and the mean particle size was $\sim 50 \mathrm{~nm}$. However, the availability of phytochemicals and metal salt concentration defines the particles size. [11]

Minimal Inhibitory Concentration

Using available reports [18, 30-33] as a basis, our study set out to find the MIC value for selected Gram-negative $E$. coli (MTCC-405) and Gram-positive B. subtilis (MTCC736) by adding resazurin dye, which shows blue in its oxidized state and pink in its reduced state. [30] Figure. 6 shows 96-well plates labeled $L_{1}$ to $L_{5}$, in which different concentrations of nanosilver were applied in relation to the antibiotic. The presence of nanosilver shows that the MIC value is $40 \mu \mathrm{g} / \mathrm{ml}$ for Gram-negative bacteria $\left(\mathrm{L}_{1}\right)$ and $60 \mu \mathrm{g} / \mathrm{ml}$ for Gram-positive bacteria $\left(\mathrm{L}_{2}\right)$ (Fig. 6) being more effective than streptomycin.

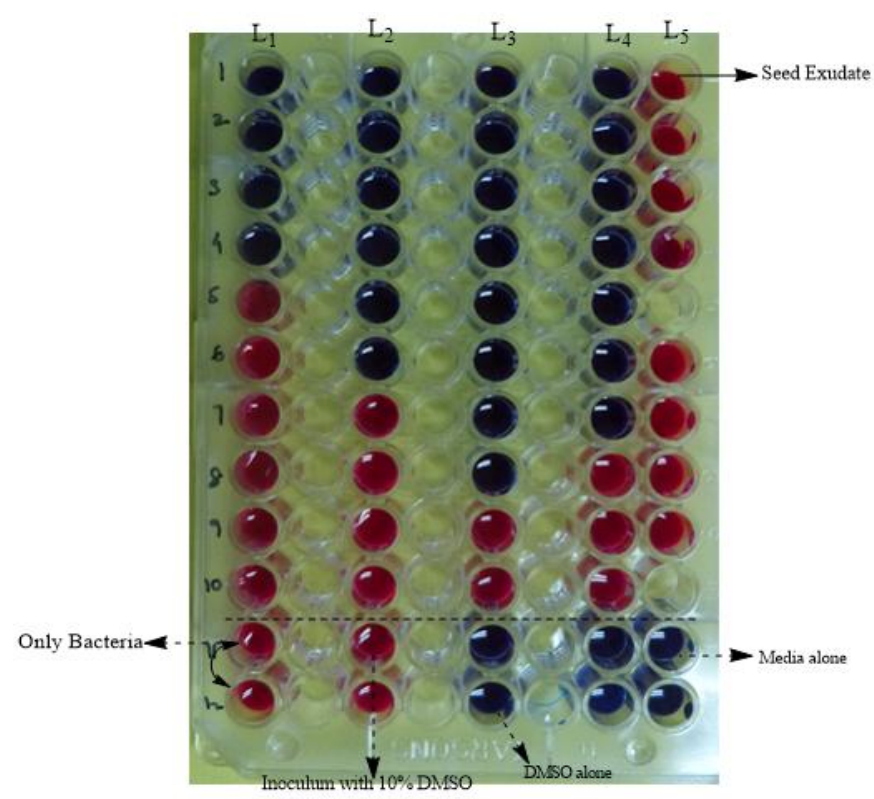

Fig. 6: 96 well resazurin plate method of nanosilver against gram negative bacteria $E$. coli and $B$. subtilis resazurin assay. $L_{1}$ and $L_{4}(1$ - 10) indicates 10 to $100 \mu \mathrm{g} / \mathrm{ml}$ of nanosilver and antibiotic supplemented with gram negative bacteria, $L_{2}$ and $L_{3}\left(\begin{array}{ll}1 & -10\end{array}\right)$ indicates 10 to $100 \mu \mathrm{g} / \mathrm{ml}$ of nanosilver and antibiotic supplemented with gram positive bacteria. $L_{5}(1-4$ and 6 to- 9$)$ supplemented with serial dilution of plant extract supplemented to gram negative and gram positive bacteria respectively.

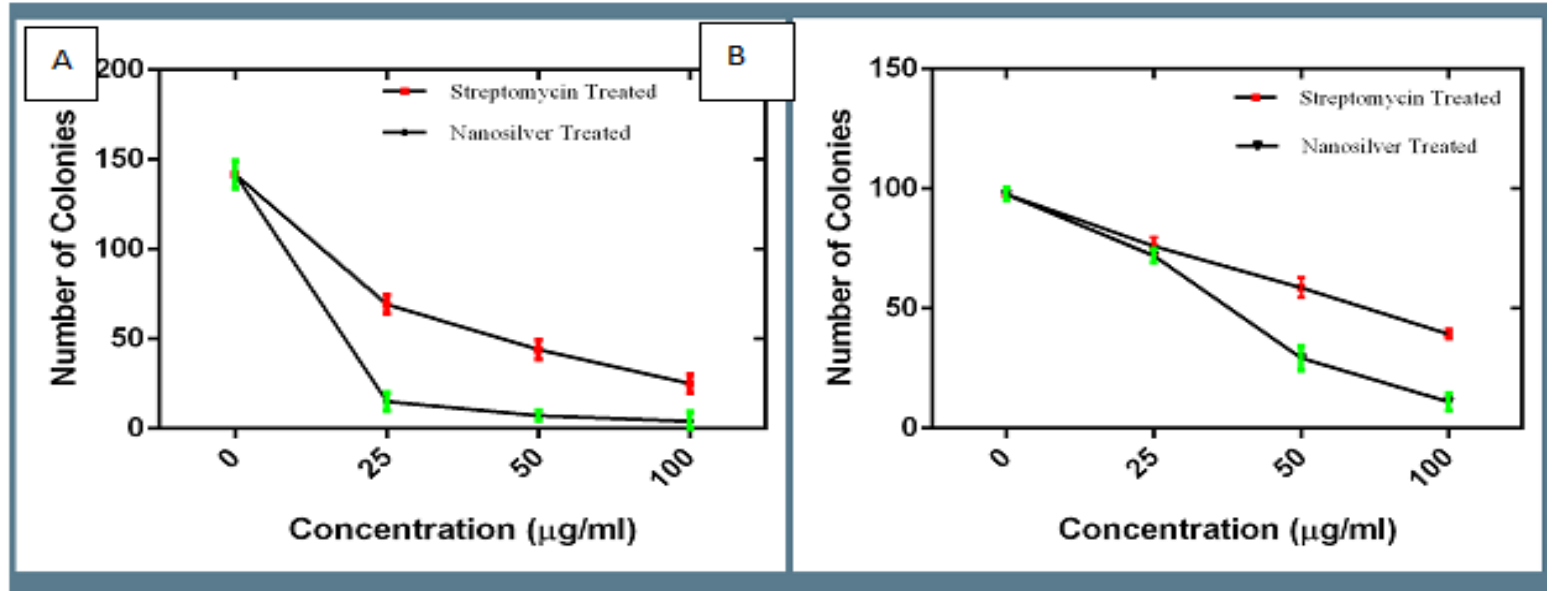

Fig. 7 (A and B): Number of colonies (growth kinetics) formed on petri plates of overnight culture of E. coli (Gram Negative) - and B. subtilis (Gram Positive) treated with different concentration of nano-silver and antibiotic

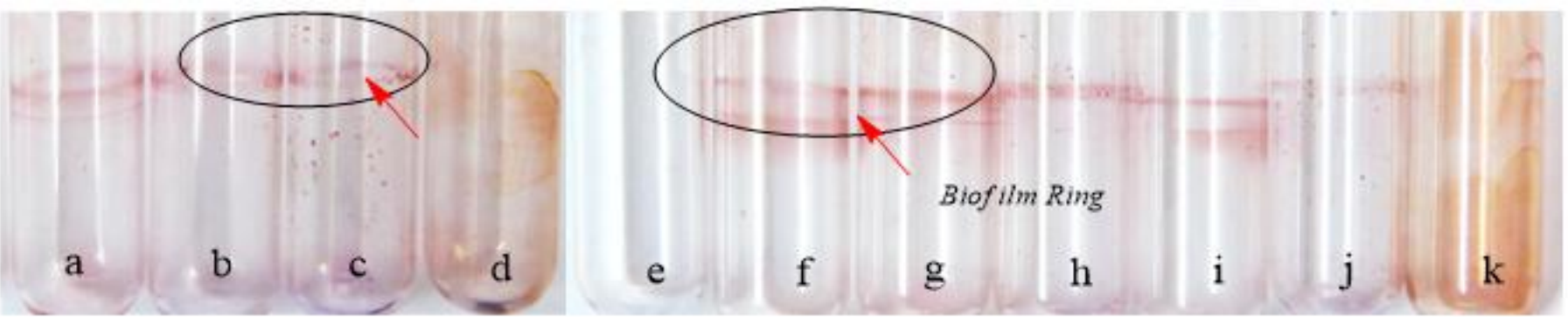

Fig. 8: Anti-biofilm activity of nanoparticles against Klebsiella pneumonia biofilm by ring assay. a - d corresponds $25-100 \mu \mathrm{g} / \mathrm{ml}$ of nanosilver, e- control (Without Bacteria), f - without nano-silver and antibiotic, $\mathrm{g}$ - j corresponds $25-100 \mu \mathrm{g} / \mathrm{ml}$ antibiotic streptomycin

Bactericidal Kinetics in the Presence of Nanosilver The efficacy of nano-silver to combat bacteria growth is based on more than the known antibiotic concentration. Colony screening method was done using different concentrations $(25,50,75$ and $100 \mu \mathrm{g} / \mathrm{ml})$ of nanosilver for the gram-negative and gram-positive bacteria to evaluate the effect of nanosilver on their growth. The kinetics of bacterial growth on agar plates (initial bacterial concentration $10^{8} \mathrm{CFU} / \mathrm{ml}$ ) with different concentrations was monitored. Figure 7 depicts the trend of a decreasing number of bacterial colonies with the increasing concentration of nanosilver. Upto 10-fold 
reduction was observed with increase in nanosilver concentration. The effect was more in E. coli (gram negative bacteria). This may be due to greater penetration of the cell wall by the nanosilver; in grampositive bacteria, the S-layer is attached to a thick peptidoglycan layer and teichoic acid, whereas in gram-negative bacteria, the S-layer is directly attached to the bacterial cell wall.

\section{Antibiofilm Activity of Nanosilver}

Biofilm infectious diseases account for $80 \%$ of microbial infections in the body [34] in which female urinary tract infections (UTIs) are one of the major recurrent and chronic infections caused by the formation of Klebsiella biofilm. [19, 35] For these reasons, we selected the Klebsiella strain to study their biofilm inhibition under different concentrations of silver nanoparticles. It is evident from our experiments that the biofilm ring formation decreased as the concentration of nanosilver increases (Fig. 8) where as in antibiotic-treated tubes, biofilm inhibition was relatively lower.

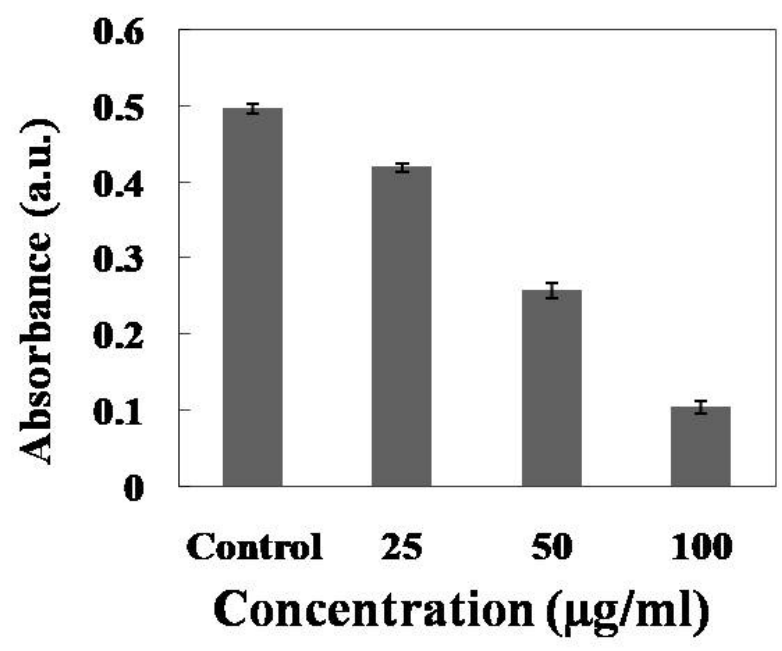

Fig. 9: Inhibitory effect of nanosilver on EPS production of Klebsiella pneumoniae biofilm. Mean values of triplicate independent expression of Mean \pm SD are shown.
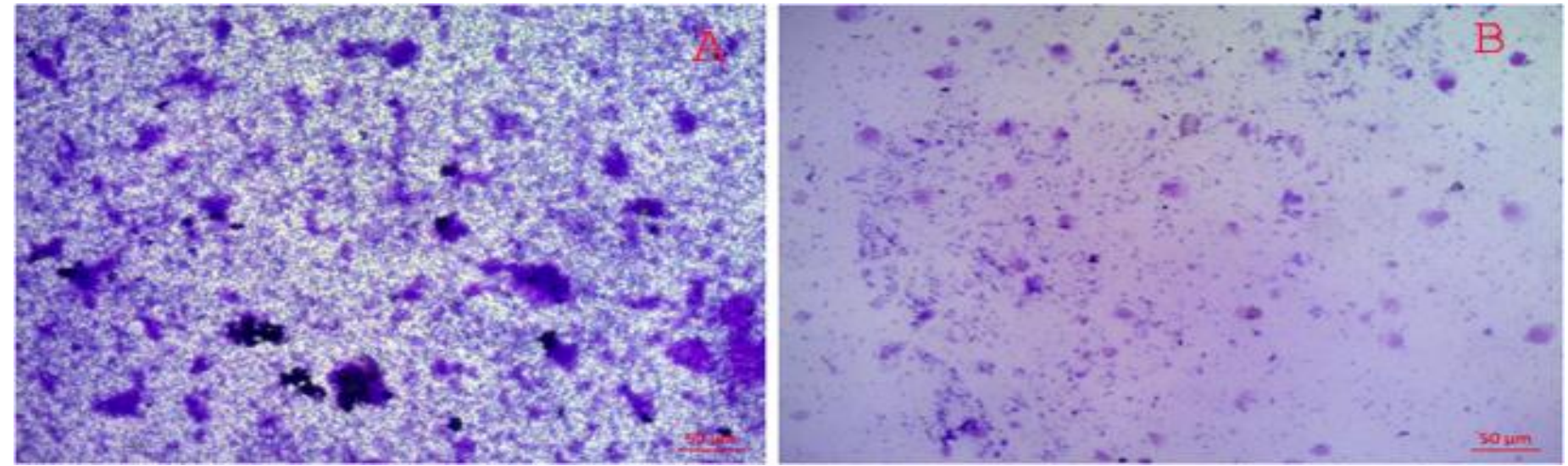

Fig. 10: Light microscopic images at $100 \times$ demonstrate the inhibition of Klebsiella pneumoniae preformed biofilm

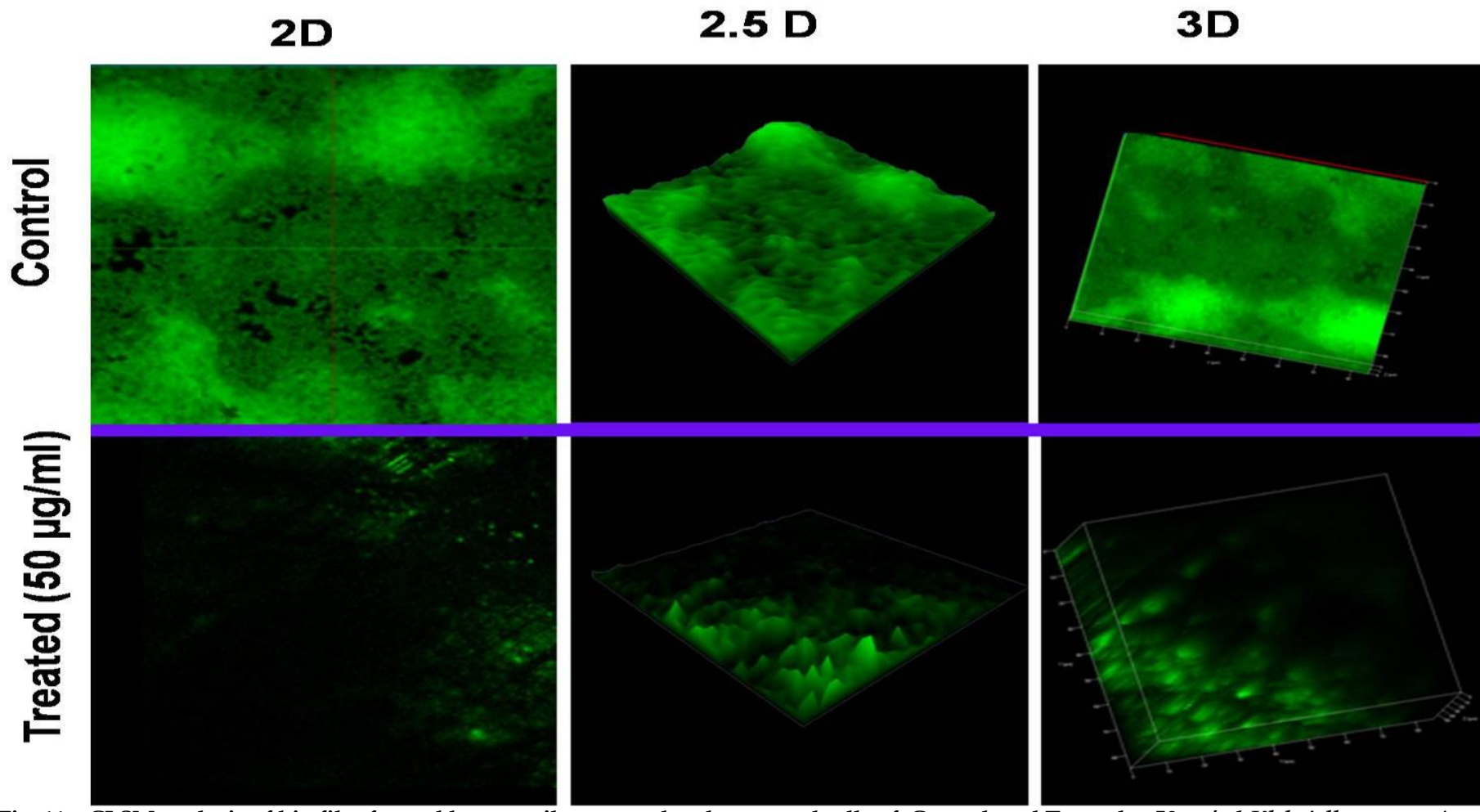

Fig. 11: CLSM analysis of bio film formed by nanosilver treated and untreated cells of Control and Treated at $50 \mu \mathrm{g} / \mathrm{ml}$ Klebsiella pneumoniae 

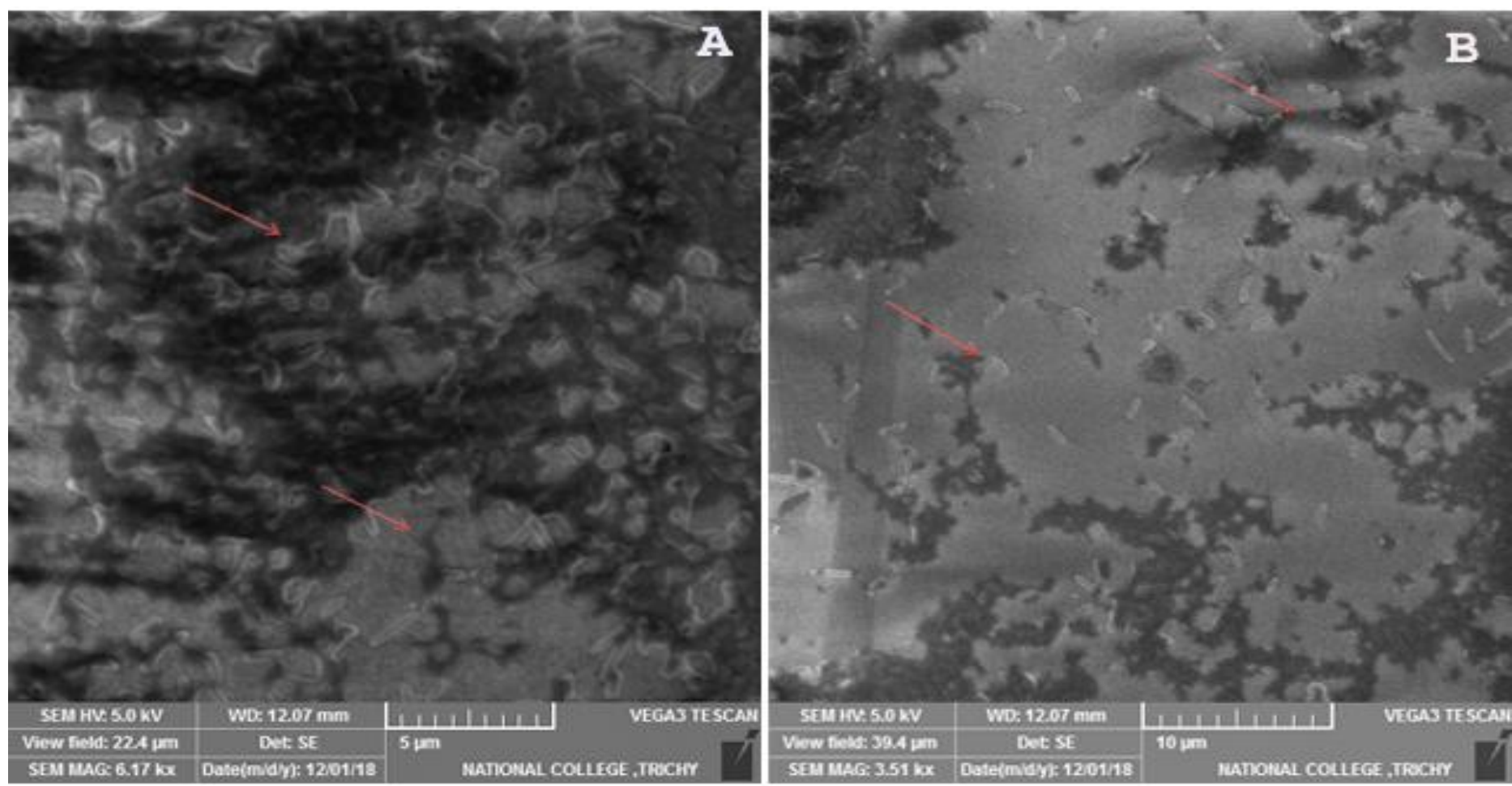

Fig. 12: Scanning Electron Microscope image of Klebsiella pneumoniae biofilm Red Arrow in (A). Control indicates the EPS forming matrix (B) Treated $(50 \mu \mathrm{g} / \mathrm{ml})$

Table. 2: Kinetics of inhibition of Klebseilla pneumonia biofilm by different concentrations of nano-silver and antibiotics.

\begin{tabular}{cccccccccc}
\hline \multirow{2}{*}{ Concentration $(\mu \mathrm{g} / \mathrm{ml})$} & Untreated $(\boldsymbol{\mu g} / \mathbf{m l})$ & \multicolumn{3}{c}{ Nanosilver $(\boldsymbol{\mu g} / \mathbf{m l})$} & \multicolumn{4}{c}{ Streptomycin $(\boldsymbol{\mu g} / \mathbf{m l})$} \\
\cline { 2 - 8 } & $\mathbf{0}$ & $\mathbf{2 5}$ & $\mathbf{5 0}$ & $\mathbf{7 5}$ & $\mathbf{1 0 0}$ & $\mathbf{2 5}$ & $\mathbf{5 0}$ & $\mathbf{7 5}$ & $\mathbf{1 0 0}$ \\
\hline \multirow{2}{*}{ Absorbance (a.u.) } & \multirow{2}{*}{$0.96 \pm 0.02$} & $0.35 \pm$ & \multirow{2}{*}{$0.30 \pm 0.00$} & $0.23 \pm$ & $0.17 \pm$ & $0.59 \pm$ & $0.41 \pm$ & $0.32 \pm$ & $0.26 \pm$ \\
& & 0.06 & & 0.06 & 0.02 & 0.06 & 0.04 & 0.05 & 0.10 \\
\hline
\end{tabular}

Values represent mean of data collected from three independent experiments Mean values of triplicate independent expression of Mean \pm SD are shown.

The growth kinetics of Klebsiella was assayed with different concentrations of nanosilver using a microplate assay developed by Maldonado et al [36] with small modifications, and the capability of nanosilver to inhibit the biofilm was studied by taking the OD at 540 $\mathrm{nm}$. The results are summarized in Table. 2. Recently Ahmed et al ${ }^{[2]}$ reported clinically isolated Klebsiella biofilm inhibition by preventing early colonization, and our results correlate with these previous reports of Shakibaie et al. ${ }^{[3]}$ At this stage, we cannot explain the mechanism behind nanosilver's ability to inhibit biofilm formation, but recently Beyth et al ${ }^{[38]}$ explained that nanosilver may electrostatically interact with bacteria, causing membrane disruption and leading to the formation of more free radicles. Ultimately, this leads to protein destruction.

EPS synthesis plays a major role in creating a matrix to form biofilms. [21] We performed EPS quantification to learn the effects of nanosilver treatment on biofilm formation. The results showed that EPS was reduced to one-fifth of the control $(P<0.05)$ with an increase in concentration of nanosilver $(0,25,50,100 \mu \mathrm{g} / \mathrm{ml})$ (Fig. 9). Even though EPS is essential to the formation of biofilm, to date, very few studies are available on preventing EPS formation to reduce Klebsiella biofilm. Though our results are comparable to the previous study wherein essential oil from C. tamala and bacterial extracts from marine sources inhibit biofilm activity by reducing EPS formation, present results are different in the extent of EPS reduction. Figure 10 shows the results of a microscopic analysis, which confirmed that the maximum reduction of biofilm occurred when the nanosilver was at its highest concentration levels. CLSM was also performed to confirm the morphology and inhibition of biofilm in support of light microscopy data, and the inhibition of biofilms was evident in the treated samples when compared with the control (Fig. 11).

Due to its high magnification and resolution, SEM revealed that there is destruction in biofilm formation after treatment with nanosilver (Fig. 12). To the best of our knowledge, this is the first report on preformed biofilm inhibition of Klebsiella; earlier studies have merely reported that the prevention of EPS synthesis will stop biofilm formation in other genera. [21,39-40]

Based on the present results to further validate the effect of nano-particles and the use of seed exudates, it is recommended that additional studies be carried out with

a) More number of gram positive and gramnegative bacteria

b) Seed coat exudates from other plant sources

c) Nanoparticles other than silver. 


\section{ACKNOWLEDGEMENTS}

Author is grateful to the CSIR for providing CSIR Senior Research Fellowship (09/475(0201)/2018-EMR-I) and the support is duly acknowledged. We also thank Dr. D. Saravanan, Coordinator and application specialist Ms. Kavitha, National College Instrumentation Facility (NCIF) for helping in SEM analysis and also, we grateful to the CLSM facility provided by the DST-PURSE scheme [SR/FT/LS113/2009] to Bharathidasan University.

\section{REFERENCES}

1. Gemmell CG, Edwards DI, Fraise AP, Gould FK, Ridgway GL, Warren RE, Chemotherapy JWPotBSfA. Guidelines for the prophylaxis and treatment of methicillin-resistant.2006 Staphylococcus aureus (MRSA) infections in the UK J Antimicrob Chemother. 2006; 57: 589-608.

2. Ahmed A, Khan AK, Anwar A, Ali SA, Shah MR. Biofilm inhibitory effect of chlorhexidine conjugated gold nanoparticles against Klebsiella pneumoniae Microb Pathog. 2016; 98:50-56.

3. Balouiri M, Sadiki M, Ibnsouda SK. Methods for in vitro evaluating antimicrobial activity: A review Journal of Pharmaceutical Analysis. 2016; 6:71-79.

4. Rajans R, Chandran K, Harper SL, Yun S-I, Kalaichelvan PT. Plant extract synthesized silver nanoparticles: an ongoing source of novel biocompatible materials Industrial Crops and Products 2015; 70:356-373.

5. Iqbal M, Raja NI, Wattoo FH, Hussain M, Ejaz M. Assessment of Green Synthesized Silver Nanoparticles in Wheat Seedlings at the Anatomical Level in Relation to Their Uptake, Translocation, and Accumulation. Iran j sci technol a. 2018; 1-11.

6. Sathishkumar G, Gobinath C, Karpagam K, Hemamalini V, Premkumar K, Sivaramakrishnan S. Phyto-synthesis of silver nanoscale particles using Morinda citrifolia $\mathrm{L}$. and its inhibitory activity against human pathogens Colloids and Surfaces B. Biointerfaces. 2012; 95:235-240.

7. Mittal AK, Chisti Y, Banerjee UC. Synthesis of metallic nanoparticles using plant extracts. Biotechnology advances 2013; 31:346-356.

8. Khatoon N, Ahmad R, Sardar M. Robust and fluorescent silver nanoparticles using Artemisia annua: biosynthesis, characterization and antibacterial activity. Biochemical Engineering Journal. 2015; 102:91-97.

9. Muthukrishnan S, Bhakya S, Kumar TS, Rao M. Biosynthesis, characterization and antibacterial effect of plant-mediated silver nanoparticles using Ceropegia thwaitesii-an endemic species. Industrial Crops and Products. 2015; 63:119-124.

10. Sundararajan B, Ranjitha Kumari BD. Novel synthesis of gold nanoparticles using Artemisia vulgaris L. leaf extract and their efficacy of larvicidal activity against dengue fever vector Aedes aegypti L. J. Trace Elem Med Bio. 2017; 43:187-196.

11. Gallucci MN, Fraire JC, Maillard AP, Páez PL, Martínez IM, Miner EV, Coronado EA, Dalmasso PR. Silver nanoparticles from leafy green extract of Belgian endive (Cichorium intybus L. var. sativus): Biosynthesis, characterization, and antibacterial activity. Materials Letters. 2017; 15:197:98-101.

12. Sundararajan B, Mahendran G, Thamaraiselvi R, Kumari BR. Biological activities of synthesized silver nanoparticles from Cardiospermum halicacabum L Bulletin of Materials Science. 2016; 39:423-431.

13. Kumar V, Yadav SC, Yadav SK. Syzygium cumini leaf and seed extract mediated biosynthesis of silver nanoparticles and their characterization. J Chem Technol Biotechnol 2010; 85:1301-1309.

14. Lukman AI, Gong B, Marjo CE, Roessner U, Harris AT. Facile synthesis, stabilization, and anti-bacterial performance of discrete Ag nanoparticles using Medicago sativa seed exudates. J Colloid Interface Sci. 2011; 353:433-444.
15. Ahmad F, Khan RA, Rasheed S. Preliminary screening of methanolic extracts of Celastrus paniculatus and Tecomella undulata for analgesic and anti-inflammatory activities. Journal of ethnopharmacology 1994; 42:193-198.

16. Ainsworth EA, Gillespie KM. Estimation of total phenolic content and other oxidation substrates in plant tissues using Folin-Ciocalteu reagent. Nature protocols. 2007; 2:875-877.

17. Rajasekharreddy P, Usha Rani P, Sreedhar B. Qualitative assessment of silver and gold nanoparticle synthesis in various plants: a photobiological approach Journal of Nanoparticle Research. 2010; 12:1711-1721.

18. Elshikh M, Ahmed S, Funston S, Dunlop P, McGaw M, Marchant R, Banat IM. Resazurin-based 96-well plate microdilution method for the determination of minimum inhibitory concentration of biosurfactants. Biotechnology letters. 2016; 38:1015-1019.

19. Kumon H. Management of Biofilm Infections in the Urinary Tract World Journal of Surgery. 2000; 24:1193-1196.

20. Christensen GD, Simpson WA, Bisno AL, Beachey EH. Adherence of slime-producing strains of Staphylococcus epidermidis to smooth surfaces. Infection and Immunity. 1982; 37:318-326.

21. Farisa Banu S et al. Antivirulent Properties of Underexplored Cinnamomum tamala Essential Oil and Its Synergistic Effects with DNase against Pseudomonas aeruginosa Biofilms-An In Vitro Study. Frontiers in microbiology. 2017; 8:1144.

22. Nithya C, Begum MF, Pandian SK. Marine bacterial isolates inhibit biofilm formation and disrupt mature biofilms of Pseudomonas aeruginosa PAO1. Applied microbiology and biotechnology. 2010; 88:341-358.

23. Nithya C, Devi MG, Karutha Pandian S. A novel compound from the marine bacterium Bacillus pumilus S6-15 inhibits biofilm formation in Gram-positive and Gram-negative species. Biofouling. 2011; 27:519-528.

24. Prasad R. Synthesis of silver nanoparticles in photosynthetic plants. Journal of Nanoparticles. 2014; Article ID 963961, 8 pages.

25. Chung I-M, Park I, Seung-Hyun K, Thiruvengadam M, Rajakumar G. Plant-mediated synthesis of silver nanoparticles: their characteristic properties and therapeutic applications. Nanoscale research letters 2016; 11:40.

26. Shabnam N, Pardha-Saradhi P, Sharmila P. Phenolics impart $\mathrm{Au} 3+$-stress tolerance to cowpea by generating nanoparticles. PloS one 2014; 9:e85242.

27. Coronado EA, Encina ER, Stefani FD. Optical properties of metallic nanoparticles: manipulating light, heat and forces at the nanoscale. Nanoscale 2011; 3:4042-4059.

28. Philip D. Green synthesis of gold and silver nanoparticles using Hibiscus rosa sinensis. Physica E: Low-Dimensional Systems and Nanostructures 2010; 42:1417-1424.

29. Poovizhi J, Krishnaveni B. Synthesis, characterization and antimicrobial activity of zinc oxide nanoparticles synthesized from Calotropis procera. International Journal of Pharmaceutical Sciences and Drug Research. 2015; 7(5): 42531.

30. Nateche F, Martin A, Baraka S, Palomino JC, Khaled S, Portaels F. Application of the resazurin microtitre assay for detection of multidrug resistance in Mycobacterium tuberculosis. Algiers J Med Microbiol. 2006; 55:857-860

31. Mayers D. Antimicrobial Drug Resistance: Clinical and Epidemiological Aspects vol 2. Springer Science \& Business Media, 2009.

32. Sánchez JGB, Kouznetsov VV. Antimycobacterial susceptibility testing methods for natural products research. Brazilian Journal of Microbiology 2010; 41: 270-27.

33. Yemoa A et al. Buruli ulcer: a review of in vitro tests to screen natural products for activity against Mycobacterium ulcerans. Planta Med. 2011; 77:641-646.

34. Hall-Stoodley L, Costerton JW, Stoodley P. Bacterial biofilms: from the natural environment to infectious diseases Nature reviews microbiology 2004; 2:95-108.

35. Di Martino P, Cafferini N, Joly B, Darfeuille-Michaud A. Klebsiella pneumoniae type 3 pili facilitate adherence and 
Anil Kumar Moola et al. / Preparation, Characterization of Silver-Nanoparticles from Seed Coat Exudates......

biofilm formation on abiotic surfaces. Research in microbiology 2003; 154:9-16.

36. Maldonado N, Silva de Ruiz C, Cecilia M, Nader-Macias M. A simple technique to detect Klebsiella biofilm-formingstrains. Inhibitory potential of Lactobacillus fermentum CRL 1058 whole cells and products. Communicating current research and educational topics and Trends in Applied Microbiology 2007; 52-59.

37. Shakibaie M, Forootanfar H, Golkari $\mathrm{Y}$, MohammadiKhorsand T, Shakibaie MR. Anti-biofilm activity of biogenic selenium nanoparticles and selenium dioxide against clinical isolates of Staphylococcus aureus, Pseudomonas aeruginosa, and Proteus mirabilis. J Trace Elem Med Biol. 2015; 29:235-241.
38. Beyth N, Houri-Haddad Y, Domb A, Khan W, Hazan R. Alternative antimicrobial approach: nano-antimicrobial materials. Evidence-Based Complementary and Alternative Medicine 2015; Article ID 246012, 16 pages.

39. LewisOscar F, MubarakAli D, Nithya C, Priyanka R, Gopinath V, Alharbi NS, Thajuddin N. One pot synthesis and anti-biofilm potential of copper nanoparticles (CuNPs) against clinical strains of Pseudomonas aeruginosa. Biofouling. 2015; 31:379-391.

40. Gomes LC, Mergulhão FJ. SEM Analysis of Surface Impact on Biofilm Antibiotic Treatment. Scanning. 2017; Article ID 2960194, 7 pages.

HOW TO CITE THIS ARTICLE: Moola AK, Balasubramani S, Nithya C, Bollipo Diana RK. Preparation, Characterization of Silver-Nanoparticles from Seed Coat Exudates of Celastrus paniculatus Willd. and Their Bactericidal and Biofilm Inhibition Effects. Int. J. Pharm. Sci. Drug Res. 2019; 11(5): 164-173. DOI: 